\title{
Short communication: Lactose enhances bile tolerance of yogurt culture bacteria
}

\author{
Behannis Mena* and Kayanush Aryana ${ }^{1}$ \\ ${ }^{*}$ School of Agriculture and Food, Faculty of Veterinary and Agricultural Sciences, The University of Melbourne, Parkville, VIC 3010, Australia \\ †School of Nutrition and Food Sciences, Louisiana State University Agricultural Center, Baton Rouge 70803
}

\begin{abstract}
Lactose is an energy source for culture bacteria. Bile tolerance is an important probiotic property. Our aim was to elucidate the effect of lactose on bile tolerance of yogurt starter culture Lactobacillus bulgaricus LB-12 and Streptococcus thermophilus ST-M5. Bile tolerance of pure cultures was determined using $0.3 \%$ oxgall in MRS THIO broth (Difco, Becton Dickinson, Sparks, MD) for L. bulgaricus and $0.3 \%$ oxgall in M17 broth (Oxoid, Basingstoke, UK) for Strep. thermophilus. Lactose was added to both broths at 0 (control), 1, 3, and $5 \%$ (wt/vol) broth. Dilutions were plated hourly for 12 h. Experiments were replicated 3 times. At 2, 4, and 12 $\mathrm{h}$ of incubation, lactose incorporated at all amounts, 1,3 , and $5 \%$ (wt/vol), showed higher counts of Strep. thermophilus ST-M5 compared with the control. Lactose use at $5 \%$ (wt/vol) significantly enhanced bile tolerance of both L. bulgaricus and Strep. thermophilus compared with control.
\end{abstract}

Key words: lactose, bile tolerance, yogurt starter culture

\section{Short Communication}

Bile is discharged in the small intestine and it destroys the cell membranes of bacteria, lowering their survival (Succi et al., 2005). Major components of the bacterial cell membrane are lipids and fatty acids. Changes in cell membrane components influence cell viability, permeability, and interactions between the environment and bacterial cell membrane (Succi et al., 2005). Tolerance to bile is an essential probiotic attribute. Bile concentration of 0.15 to $0.3 \%$ is appropriate for selection of probiotics (Goldin and Gorbach 1992).

Lactose or milk sugar is a major solids component in fluid milk and nonfat dry milk. Yogurt is made from milk fermented using yogurt culture bacteria Lacto-

Received September 29, 2017.

Accepted November 3, 2017.

${ }^{1}$ Corresponding author: karyana@agcenter.lsu.edu bacillus bulgaricus and Streptococcus thermophilus. From outside the bacterial cell, lactose is transferred into the Strep. thermophilus cell by membrane-bound $\beta$-galactoside permease (Neves et al., 2005). Once inside the bacterial cell, lactose is cleaved by $\beta$-galactosidase into glucose and galactose (Venkatesh et al., 1993).

Lactose is an energy source for living organisms. As bile and lactose influence bacterial cell viability in opposite ways, one would question whether lactose would affect bile tolerance of yogurt culture bacteria. To the best of our knowledge, no reports exist on the effect of lactose on yogurt culture bacterial response to bile. The aim of the current study was to determine the influence of various concentrations of lactose on the bile tolerance of the yogurt starter culture.

Bile tolerance was determined according to Dave and Shah (1996) and Pereira and Gibson (2002) with minor changes. Sodium thioglycolate (Acros Organics, Fair Lawn, NJ) $0.2 \%$ (wt/vol) was used as oxygen scavenger to make THIO de Man, Rogosa, Sharpe (MRS) broth (Difco, Becton Dickinson, Sparks, MD). The THIO MRS broth was prepared for L. bulgaricus. The M17 broth (Oxoid, Basingstoke, UK) was prepared for Strep. thermophilus. The THIO MRS and M17 broths were supplemented individually with $0.3 \%$ (wt/vol) oxgall (bovine bile; US Biological, Swampscott, MA). Lactose was incorporated into both broths at 0 (control), 1,3 , and $5 \%$ (wt/vol). Both broths were inoculated individually with $1 \%$ (vol/vol) of freshly thawed pure culture L. bulgaricus LB-12 and Strep. thermophilus STM5 (Chr. Hansen, Milwaukee, WI). Inoculated broths were incubated aerobically for $12 \mathrm{~h}$ at $37^{\circ} \mathrm{C}$ for Strep. thermophilus ST-M5 and anaerobically at $43^{\circ} \mathrm{C}$ for $L$. bulgaricus LB-12.

Serial dilutions of inoculated broths were conducted hourly in $0.1 \%$ (wt/vol) peptone water. Pour plating was conducted in duplicate. Lactobacilli MRS agar was used for the enumeration of $L$. bulgaricus LB-12 (Dave and Shah, 1997) and M17 agar was used for the enumeration of Strep. thermophilus ST-M5 (Jordano et al., 1992). The L. bulgaricus LB-12 petri dishes were anaerobically incubated for $72 \mathrm{~h}$ at $43^{\circ} \mathrm{C}$. The Strep. 


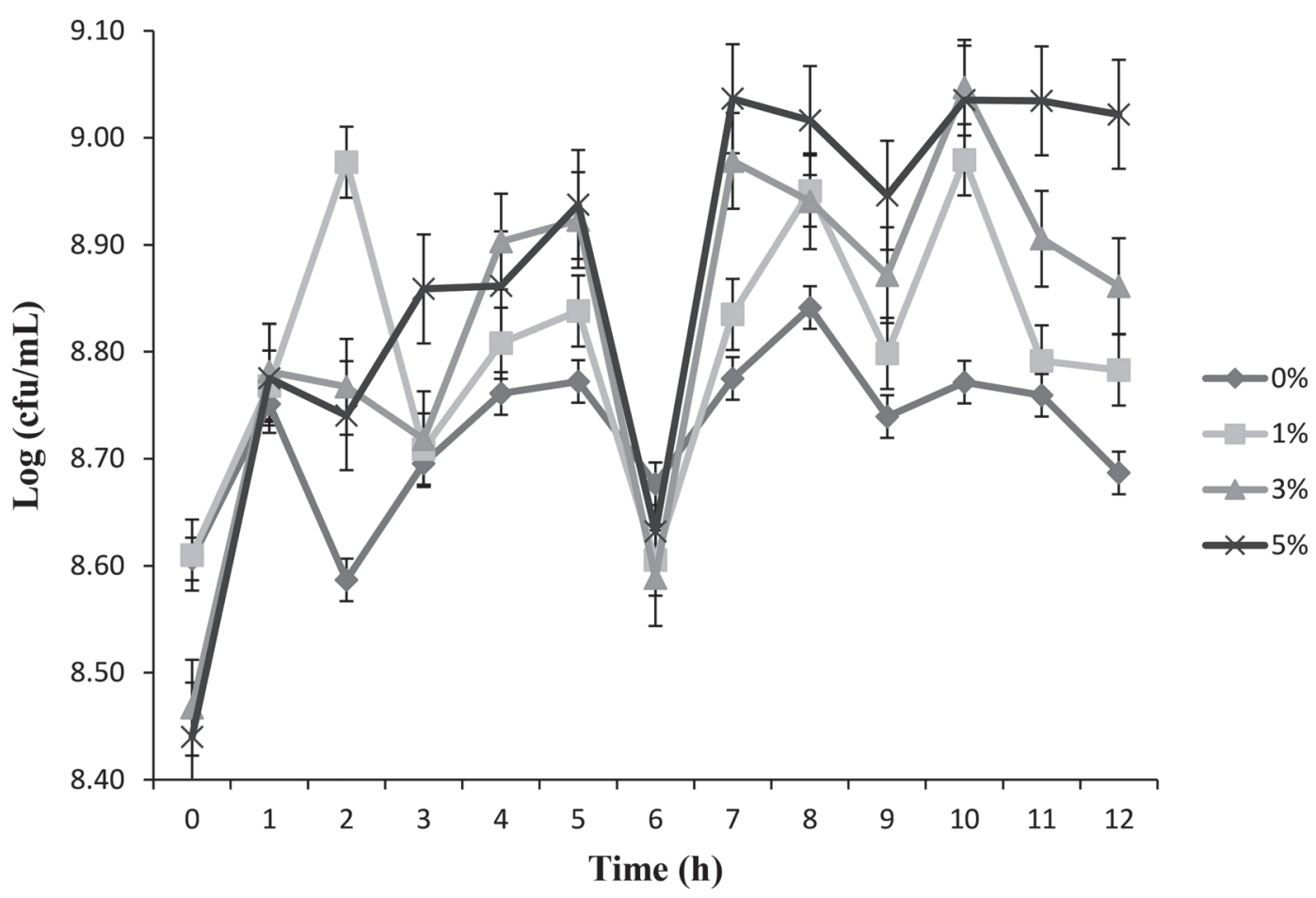

Figure 1. Bile tolerance of Streptococcus thermophilus ST-M5 as influenced by the addition of 0 (control), 1, 3, or $5 \%$ lactose over the incubation period of $12 \mathrm{~h}$. Data are expressed as means $\pm \mathrm{SE}$.

thermophilus ST-M5 petri dishes were aerobically incubated for $24 \mathrm{~h}$ at $37^{\circ} \mathrm{C}$. The colonies were counted after the incubation period. All experiments were replicated 3 times.

Bacterial culture counts were converted to $\log _{10}$ scale before data analyses; Proc Mixed of the SAS (version 9.3, SAS Institute Inc., Cary, NC) was used to analyze data. Differences between least square means were determined at $\alpha=0.05$ for the main effects (lactose concentration and time) and interaction effects (lactose concentration $\times$ time).

The bile tolerance of Strep. thermophilus ST-M5 as affected by lactose addition over the incubation of 12 $\mathrm{h}$ is presented in Figure 1. We noted a significant $(P$ $<0.05$ ) interaction effect for lactose concentration $x$ time. The main effects, namely lactose concentration effect and time $(\mathrm{h})$, were also significant $(P<0.05)$. At $\mathrm{h} 2,4$, and 12 of incubation, lactose incorporated at 1,3 , and $5 \%$ (wt/vol) showed significantly $(P<0.05)$ higher counts in comparison to control. Gilliland and Kim (1983) found that the use of 1 and $0.5 \%$ oxgall enhanced $(P<0.01)$ the lactose-hydrolyzing activity of yogurt starter bacteria to 16.7 and 19.8 units, respectively. Martini et al. (1987) observed a 3-fold increase in lactase activity of yogurt starter culture with use of 0.5 or $1 \%$ oxgall and mentioned that bacterial cell permeability was altered when exposed to intestinal bile.
Streptococcus thermophilus ST-M5 counts at $0 \mathrm{~h}$ were subtracted from those at $12 \mathrm{~h}$ of incubation to obtain the mean log difference in the viable counts. A large number indicated higher bacterial survival. Bacterial survival was greatest (0.59 $\log \mathrm{cfu} / \mathrm{mL}$ ) for $5 \%$ (wt/ vol) lactose compared with the remaining (i.e., 0.40, 0.18 , and $0.08 \log \mathrm{cfu} / \mathrm{mL}$ for 3,1 , and $0 \%$ lactose, respectively). By increasing energy production through sugar metabolism, responses against damaging action of bile at various levels, such as fatty acid biosynthesis, bile efflux, and cell wall design, can be accomplished in lactic acid bacterial strains (Ruiz et al., 2013).

Bile tolerance of $L$. bulgaricus LB-12 as affected by addition of lactose over $12 \mathrm{~h}$ of incubation is shown in Figure 2. The interaction effect of lactose concentration $\times$ time was not significant $(P>0.05)$. The main effects, that is, lactose concentration effect and time (h), were significant $(P<0.05)$. Use of $5 \%$ (wt/vol) lactose resulted in higher $(P<0.05)$ counts compared with use of $1 \%$ (wt/vol) lactose or no lactose (control). The highest counts of L. bulgaricus LB-12 were observed during first $8 \mathrm{~h}$ of incubation. Lactobacillus bulgaricus LB-12 log colony-forming units per milliliter at $12 \mathrm{~h}$ of incubation were subtracted from counts at $0 \mathrm{~h}$ to obtain the mean log difference in viable counts. A smaller number indicated lower bacterial death. Bacterial death was the least $(0.92 \log \mathrm{cfu} / \mathrm{mL}$ ) for $5 \%$ (wt/vol) lactose 


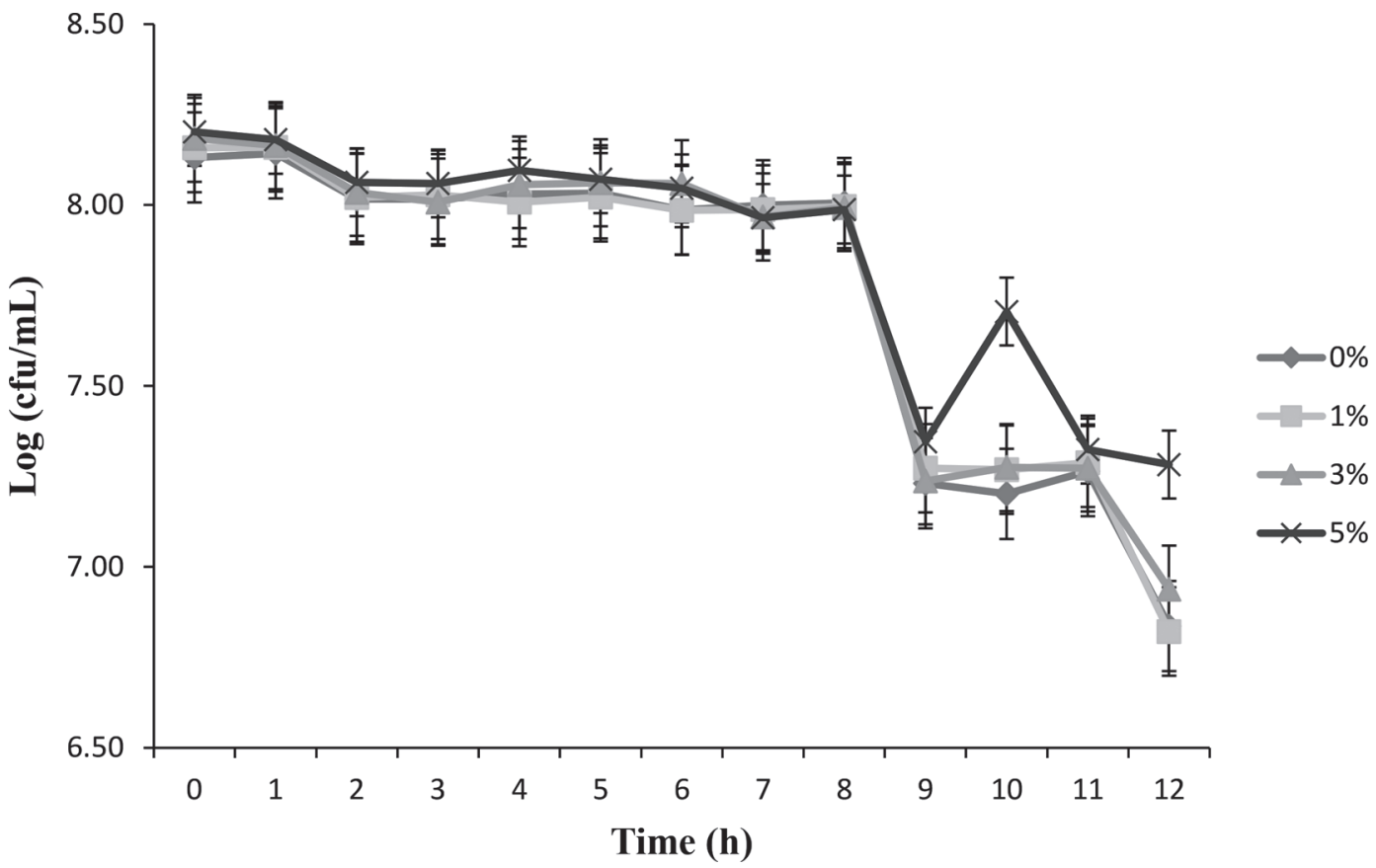

Figure 2. Bile tolerance of Lactobacillus bulgaricus LB-12 as influenced by the addition of 0 (control), 1, 3, or 5\% lactose over the incubation period of $12 \mathrm{~h}$. Data are expressed as means \pm SE.

compared with the remaining (i.e., $1.25,1.33$, and 1.29 $\log \mathrm{cfu} / \mathrm{mL}$ for 3,1 , and $0 \%$ lactose, respectively).

Lactose had a beneficial influence on bile tolerance of yogurt starter bacteria. From a manufacturing standpoint, because nonfat dry milk and whey powders contain lactose they also can be potential ingredient options to improve bile tolerances of yogurt culture bacteria.

\section{ACKNOWLEDGMENTS}

This study was funded by USDA Hatch funds and Louisiana State University Agricultural Center, Baton Rouge.

\section{REFERENCES}

Dave, R. I., and N. P. Shah. 1996. Evaluation of media for selective enumeration of Streptococcus thermophilus, Lactobacillus delbrueckii ssp. bulgaricus, Lactobacillus acidophilus, and Bifidobacteria. J. Dairy Sci. 79:1529-1536. https://doi.org/10.3168/jds.S0022 $-0302(96) 76513-X$.

Dave, R. I., and N. P. Shah. 1997. Viability of yoghurt and probiotic bacteria in yoghurts made from commercial starter cultures. Int. Dairy J. 7:31-41. https://doi.org/10.1016/S0958-6946(96)00046-5.

Gilliland, S. E. and H.S. Kim. 1983. Influence of yogurt containing live starter culture on lactose utilization in humans. Pages 113-116 in
Animal Science Research Report. Oklahoma State Beef Extension, Stillwater.

Goldin, B. R., and S. L. Gorbach. 1992. Probiotics for humans. Pages 355-376 in Probiotics, the Scientific Basis. R. Fuller, ed. Chapman \& Hall, London, UK.

Jordano, R., E. C. Serrano, M. Torres, and J. Salmeron. 1992. Comparison of three M17 media for the enumeration of Streptococcus thermophilus in fermented dairy products. J. Food Prot. 55:9991000.

Martini, M. C., G. L. Bollweg, M. D. Levitt, and D. A. Savaiano. 1987. Lactose digestion by yogurt beta-galactosidase: influence of $\mathrm{pH}$ and microbial cell integrity. Am. J. Clin. Nutr. 45:432-436.

Neves, A. R., W. A. Pool, J. Kok, O. P. Kuipers, and H. Santos. 2005. Overview on sugar metabolism and its control in Lactococcus lactis - The input from in vivo NMR. FEMS Microbiol. Rev. 29:531-554. https://doi.org/10.1016/j.femsre.2005.04.005.

Pereira, D. I., and G. R. Gibson. 2002. Cholesterol assimilation by lactic acid bacteria and Bifidobacteria isolated from the human gut. Appl. Environ. Microbiol. 68:4689-4693.

Ruiz, L., A. Margolles, and B. Sánchez. 2013. Bile resistance mechanisms in Lactobacillus and Bifidobacterium. Front. Microbiol. $4: 396$.

Succi, M., P. Tremonte, A. Reale, E. Sorrentino, L. Grazia, B. Pacifino, and R. Coppola. 2005. Bile salt and acid tolerance of Lactobacillus rhamnosus strains isolates from Parmigiano Reggiano cheese. FEMS Microbiol. Lett. 244:129-137.

Venkatesh, K. V., M. R. Okos, and P. C. Wankat. 1993. Kinetic model of growth and lactic acid production from lactose by Lactobacillus bulgaricus. Process Biochem. 28:231-241. https://doi.org/10.1016/ 0032-9592(93)80039-J. 